\title{
Friction Reduction of Palm Kernel Activated Carbon Polymer Composite by Lubricant Impregnation
}

\author{
Hilmi Amiruddin ${ }^{1,2)}$, Mohd Fadzli Bin Abdollah ${ }^{1,2)^{*}}$ and Maziah Ibrahim ${ }^{1)}$ \\ ${ }^{1)}$ Fakulti Kejuruteraan Mekanikal, Universiti Teknikal Malaysia Melaka, \\ Hang Tuah Jaya, 76100 Durian Tunggal, Melaka, Malaysia \\ ${ }^{2)}$ Centre for Advanced Research on Energy, Universiti Teknikal Malaysia Melaka, \\ Hang Tuah Jaya, 76100 Durian Tunggal, Melaka, Malaysia \\ *Corresponding author: Mohd Fadzli Bin Abdollah (mohdfadzli@utem.edu.my)
}

Manuscript received 06 March 2019; accepted 09 May 2019; published 15 December 2019

Presented at the International Tribology Conference Sendai 2019, 17-21 September, 2019

\begin{abstract}
The purpose of this research is to propose a technique for friction reduction of palm kernel activated carbon (PKAC) polymer composite by palm oil, paraffin oil and water impregnations. A biocomposite sample formed by mixing epoxy and PKAC was made using the method of powder metallurgy. Before test of dry sliding, the sample was impregnated with palm oil, paraffin oil, and water for about 1-8 days. The test of dry sliding was then conducted at room temperature and by applying constant load, sliding distance and sliding speed. The test of sustainability for checking the biocomposite's ability of maintaining the lubricant was also carried out without any more impregnation. A considerable amount of friction of lubricant-impregnated PKAC composite is reduced although there is increases in residual depth due to plastic deformation in comparison to the sample devoid of any impregnation. Water impregnation caused an unexpected rise in the coefficient of friction within the initial few hours following which it became comparatively steady. The sample impregnated with palm and paraffin oils can soak up the lubricant and sustain it for some time prior to the subsequent inflow. More decrease on the coefficient of friction and residual depth were noticed when the soaking time was raised. Besides, no wear is observed on the surface of all samples impregnated with palm oil. Thus, the application of bio-based lubricant to obtain an improved performance in comparison to the synthetic oil is more worthwhile.
\end{abstract}

\section{Keywords}

palm kernel activated carbon, biocomposite, polymer, lubricant impregnation, friction coefficient

\section{Introduction}

Lighter components contribute significantly in the improvisation of the transportation domain via the short- and long-term development, as recorded by Society of Tribologist and Lubrication Engineers (STLE) [1]. Moreover, if the components are put through relative sliding movement, they must accommodate properties like increased lifetime, high resistance to wear and low friction coefficient.

The utilisation of palm tree oil local waste for transforming refuse into valuable product will prove to be worthwhile with respect to the environmental and technological viewpoints. The preference of palm kernel activated carbon (PKAC) is on the basis of their high lubricity and hardness characteristics in comparison to other biological fortification-based polymeric composites [2,3]. Furthermore, our earlier studies [3, 4] discovered that the coefficient of friction of the polymer composite reinforced with PKAC can be reduced to 0.1 under conditions of dry sliding. Nevertheless, such a value is still not near to values of industrial self-lubricating components such as diamond-like carbon (DLC), for which the coefficient of friction is around 0.01 .

On the basis of the above analysis, research attempts have been aimed at the polymer-reinforced composites usage, in which it is utilised as tribology components like seals, gears, cams and bushes, in aerospace and automotive domains [5-9]. These components are presently fabricated using synthetic materials and potentially impact the environment negatively. Also, certain mechanisms need pre-lubrication either continually or intermittently [10]. In specific applications such as bearing, external lubrication raises issues of lubricant thinning which is a non-degradable waste [9]. To eliminate or reduce these problems, 'bio-tribo-materials' are required with reduced or no outer lubrication or even having abilities of self-lubrication. This will mainly be required in systems needed to be prelubricated, in which the component suffering friction soaks up 
the lubricant when it flows intermittently and preserves it for a long time. It will not just cause reduction in wear and coefficient of friction but also decrease the quantity of lubricant required in the mechanism. Thus, this study will prove to be pioneering in the possible use of lubricant-impregnated PKAC polymer composite as an innovative bio-tribo-material in mechanisms requiring prior or intermittent lubrication.

\section{Methodology}

\subsection{Sample fabrication}

The sample of the biocomposite was made in a disc structure ( $5 \mathrm{~mm}$ thickness and $74 \mathrm{~mm}$ diameter) by combining 70 mass $\%$ PKAC (particle of size $125 \mu \mathrm{m}$ ) with 30 mass\% epoxy, in which the ratio of hardener to resin is 1:4. The sample's weight percentage combination is the most excellent constitution with respect to their physical-mechanical characteristics as in our earlier study [2]. Further, the combination was placed into a mould and compressed with a hot-press machine at a pressure and temperature of $2.5 \mathrm{MPa}$ and $80^{\circ} \mathrm{C}$, respectively. Then, the mixture was cured for 7 days at room temperature. Abrasive paper (100, 600 and 2000 grit) was then utilised to make sure that all of the samples have arithmetic mean surface roughness, $R_{a}$ of 2 to $3 \mu \mathrm{m}$.

\subsection{Lubricant impregnation}

Palm oil, paraffin oil and water were utilised as a lubricant for the sample's impregnation preparation. Then, it was completely submerged for 1-8 days into the lubricant. Before the tribological analysis, the sample was taken out from the lubricant and wipe clean using a lab soft tissue paper to ensure that the surface remained fluidless. Moreover, weight and hardness were measured for all the samples by using microbalance and Shore D Durometer, respectively.

\subsection{Dry sliding test}

The test of dry sliding was carried out by using a ball-ondisc tribometer. Each of the tests was performed at a steady load of $5 \mathrm{~N}$, sliding distance $1000 \mathrm{~m}$ and sliding speed of 200 $\mathrm{rpm}$. The diameter of wear track is between $20 \mathrm{~mm}$ to $40 \mathrm{~mm}$. This test was performed at a functional temperature of $27^{\circ} \mathrm{C}$. EN31 ball bearing of chrome steel was used as a counter surface in this study and it had a diameter of $12.7 \mathrm{~mm}$. The force of fiction was defined by using a data logging system connected to a computer. The coefficient of friction (COF) was computed by using Eq. (1). In the meantime, the residual depth $(h)$ due to the plastic deformation was computed on the basis of spherical geometry as given in Eq. (2).

$$
\begin{aligned}
& C O F=\frac{F}{W} \\
& h=r-\sqrt{\left(r^{2}-a^{2}\right)}
\end{aligned}
$$

Where $F$ represents friction force [N], $W$ represents applied load $[\mathrm{N}], h$ represents residual depth $[\mathrm{mm}], 2 a$ represents wear scar width [mm], and $r$ represents ball bearing radius [mm].

Surface morphology was observed using an optical microscope.

\subsection{Sustainability test}

The test of sustainability was carried out with the aim to estimate the ability or period of lubricant-impregnated PKAC polymer composite to sustain the oil without any outer lubrication. Following the first test of dry sliding, the same sample was further kept in a plastic sack for 2-8 other days. The sample's weight changes were supervised under laboratory conditions, before one more test of dry sliding with equivalent conditions, using a new ball bearing.

\section{Results and discussion}

Figure 1(a) displays the palm oil, paraffin oil and water impregnation effect on the biocomposites' friction coefficient. A decrease in the friction coefficient is observed for palm and paraffin oils impregnated mechanisms. This might be due to the remaining of oil into the pores and resulted in reduction of friction coefficient. Nonetheless, water impregnation caused an unanticipated increase in the coefficient of friction within the initial few hours following which it was relatively constant. The reason for this may be rapidly loss of lubrication by water evaporation in the atmosphere. In this study, the value for unsoaked sample is only served as a datum and tested only once.

From Fig. 1(b), no wear is observed on the surface for all samples. Figure 1(c) depicts the paraffin oil, palm oil and water impregnation on the biocomposites' residual depth due to plastic deformation. It was remarkable to observe that the residual depth outcomes for all the impregnated samples were greater than those without impregnation. It is consistent with the hardness value decrease after impregnation of the sample. Lowered hardness led to decrease the yield strength which rapidly increased the plastic deformation.

Figures 2(a) and (b) additionally display the capability of the sample of the biocomposite to preserve the lubricant for some amount of time without any more impregnation. As can be observed, the impact of oil on the coefficient of friction was from 0.04 to 0.06 for 2 and 8 more days. The sample impregnated with palm oil displayed the lowest coefficient of friction from 0.04 to 0.05 . From Fig. 2(c), there is also a significant decreased in the residual depth after the sample is kept for 2 days and then remain constant after 8 days without any more impregnation. This outcome confirms that no oil loss occurred during the storage period. To confirm oil retention, samples' weight changes were measured under laboratory conditions for 2-8 days. In this study, the change in weight of the sample is not due to the wear, but it is due to the loss of lubricant. This may also directly affect the friction coefficient. As can be viewed in Fig. 3, it was noticed that there was not much weight change for the first 8 exposed days, since at the time of impregnation, the oil goes through the pores of the material [11].

The beginning of wear process is observed after the sample is kept for 2 and 8 days, which generally characterised by grooves on the worn surface of sample impregnated with water and paraffin oil, as shown in Fig. 4. However, no wear is observed on the surface of all samples impregnated with palm oil.

For additional analysis on the soaking time's effect, the sample was impregnated for 8 days with palm oil. The outcome was evaluated against the sample impregnated with palm oil for a single day. Figures 5 and 6 illustrates that there is further reduction in the coefficient of friction and residual depth. Besides, no wear is observed even after the sample was impregnated for 8 days with palm oil, as shown in Fig. 7. This might be due to more oil goes through the pores of the material when the impregnated time increases. 

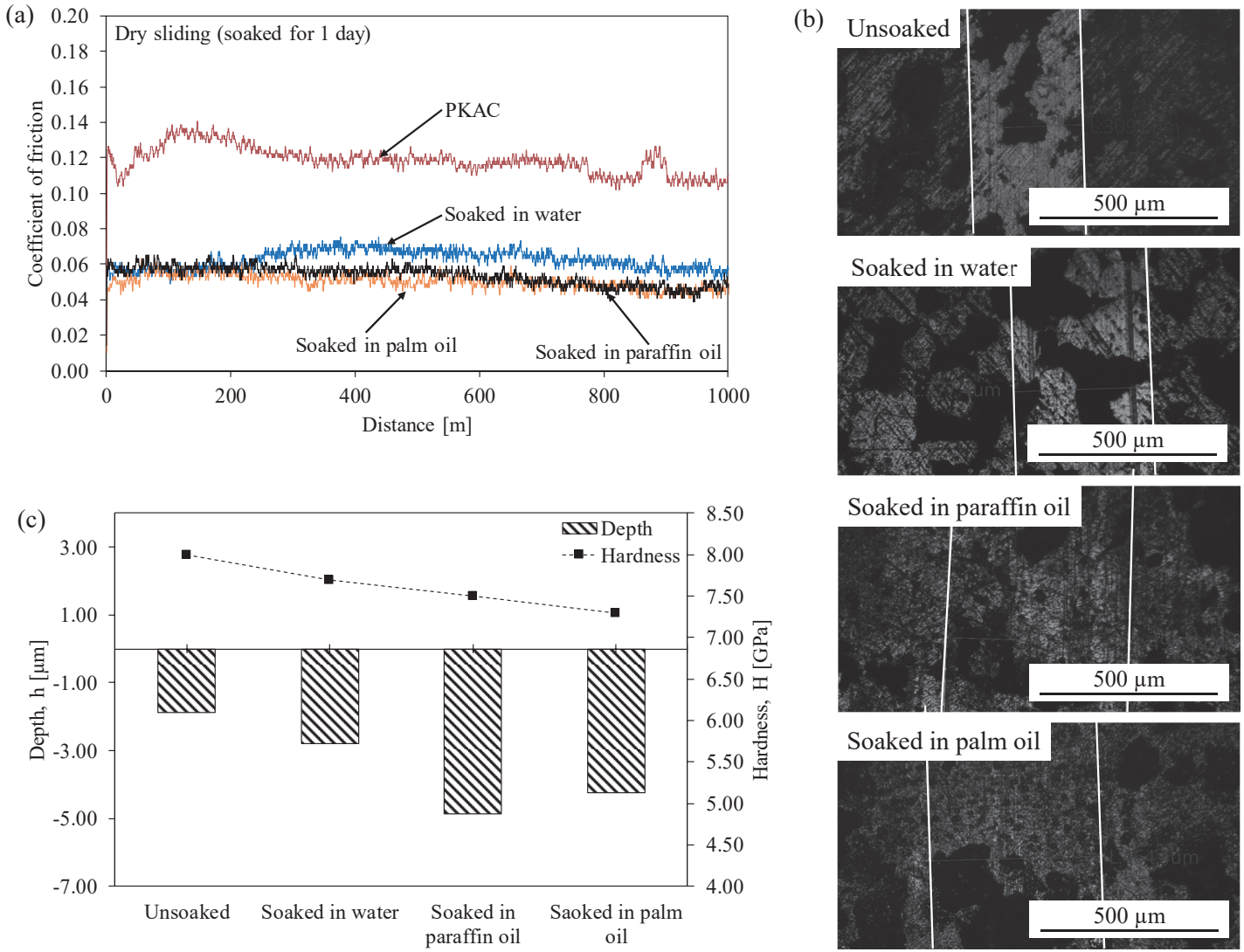

Fig. 1 Effect of palm oil, paraffin oil and water impregnations on (a) coefficient of friction, (b) surface morphology, (c) residual depth and hardness of PKAC polymer composite after soaked for 1 day. The unsoaked sample (PKAC) is only served as a datum.
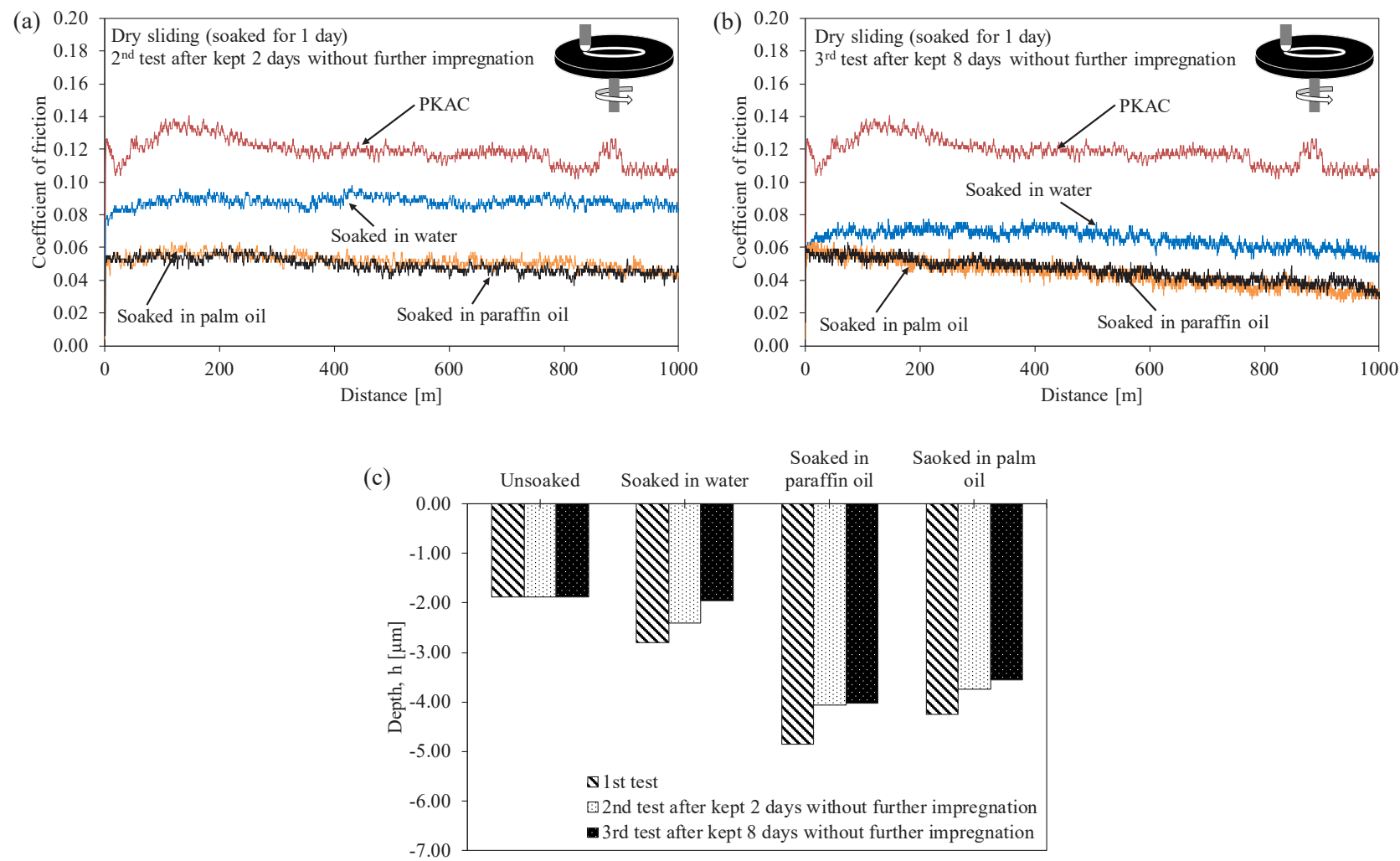

Fig. 2 EImpregnated-PKAC polymer composite after soaked for 1 day: (a) After kept 2 days without further impregnation, (b) After kept 8 days without further impregnation and (c) residual depth. The unsoaked sample (PKAC) is only served as a datum. 


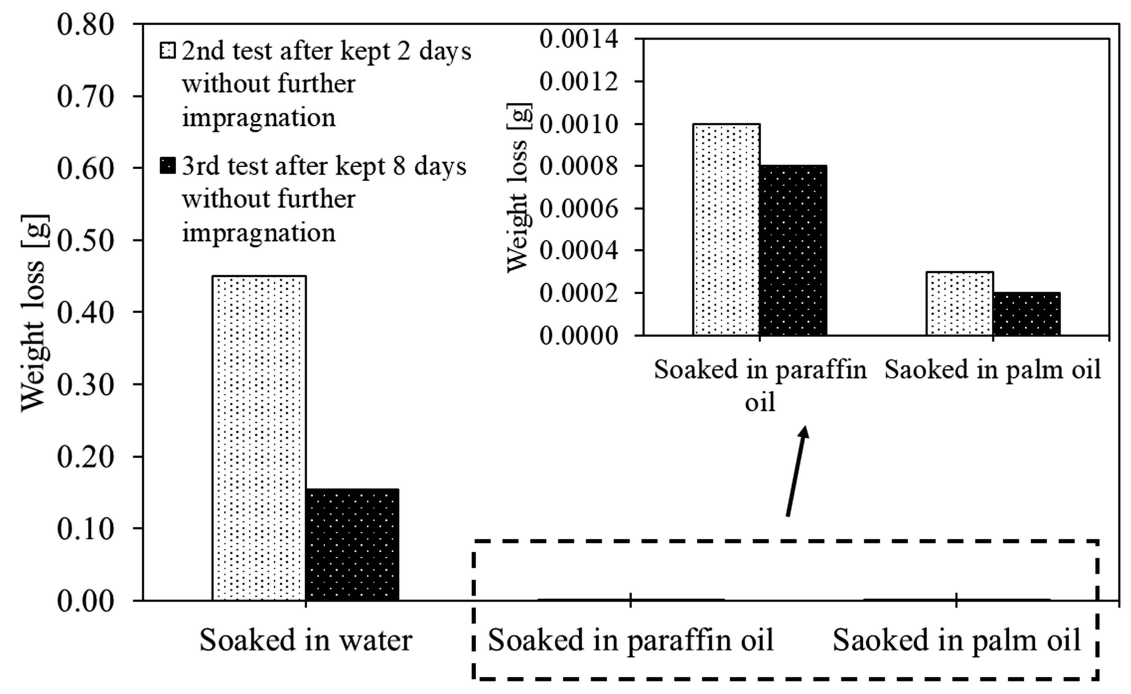

Fig. 3 Weight loss of lubricant-impregnated PKAC composite after kept for 2 days and 8 days without further impregnation

(a)
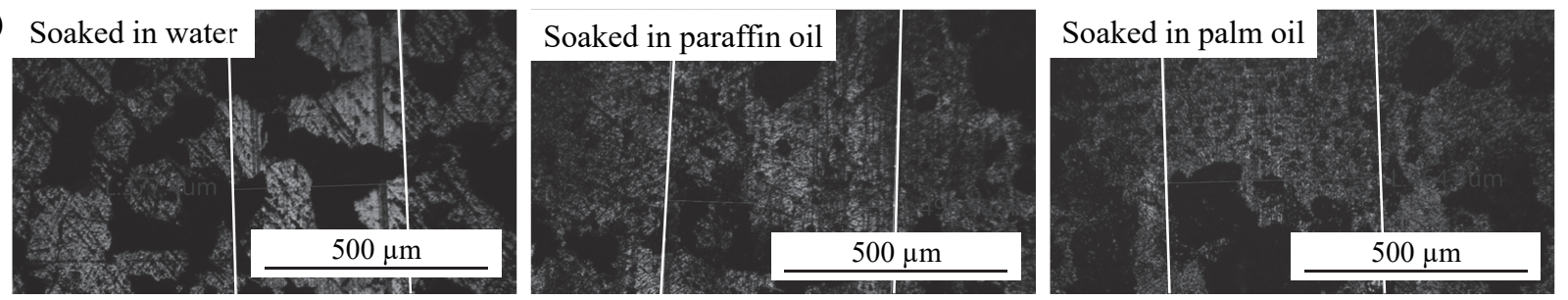

(b) Soaked in water
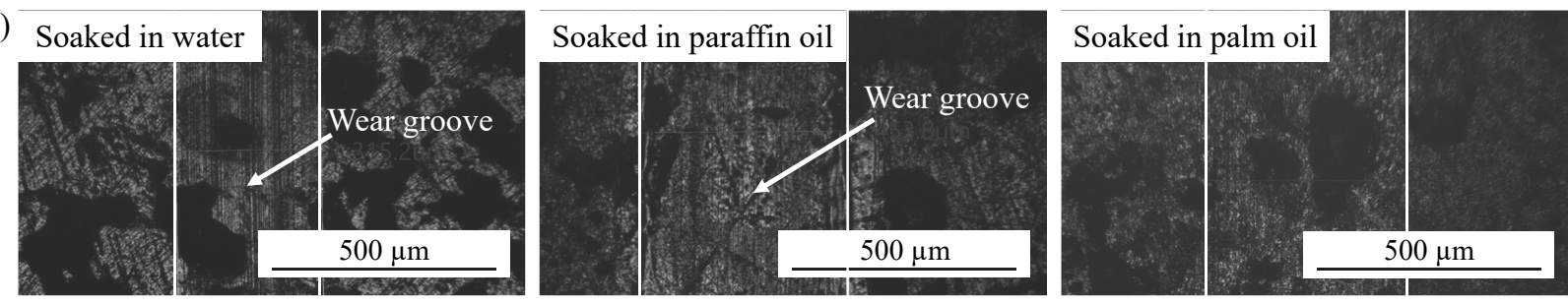

(c) Soaked in water
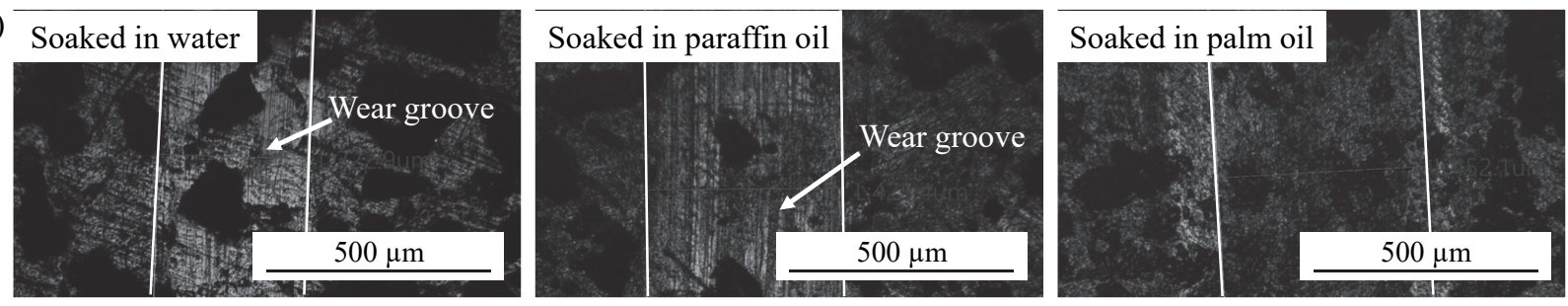

Fig. 4 Optical image of lubricant-impregnated PKAC composite after soaked for 1 day: (a) $1^{\text {st }}$ test, (b) $2^{\text {nd }}$ test after kept 2 days without further impregnation and (c) $3^{\text {rd }}$ test after kept 8 days without further impregnation 
(a)

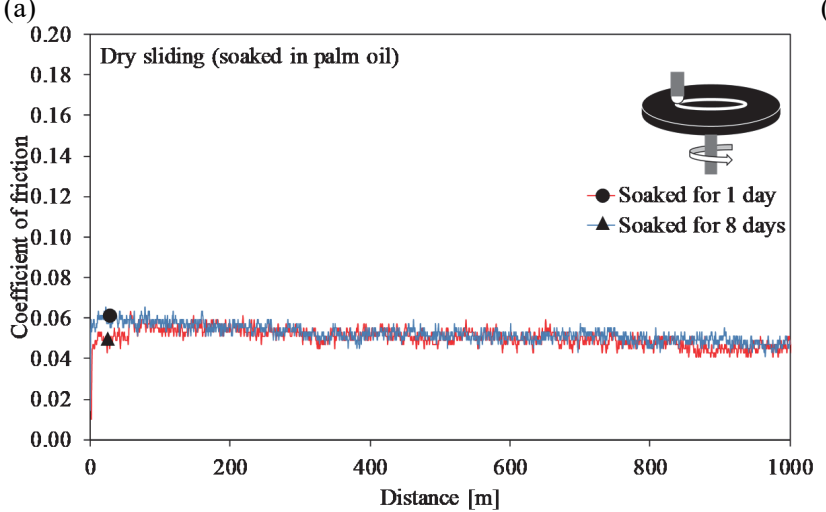

(b)

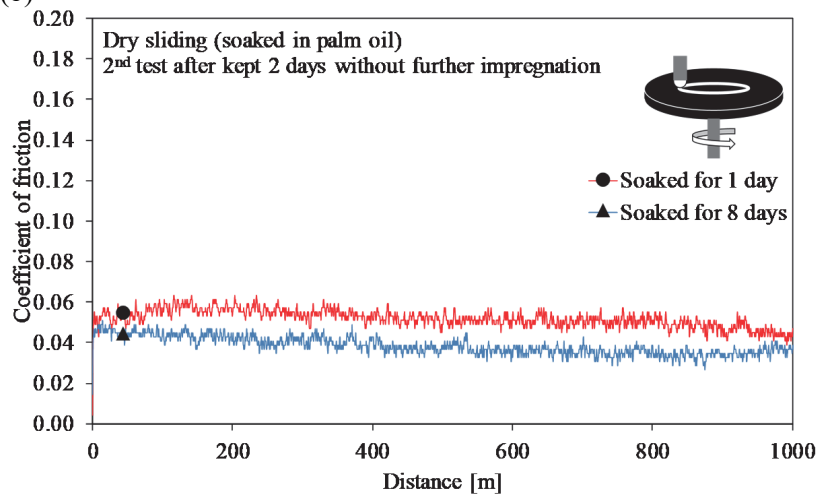

(c)

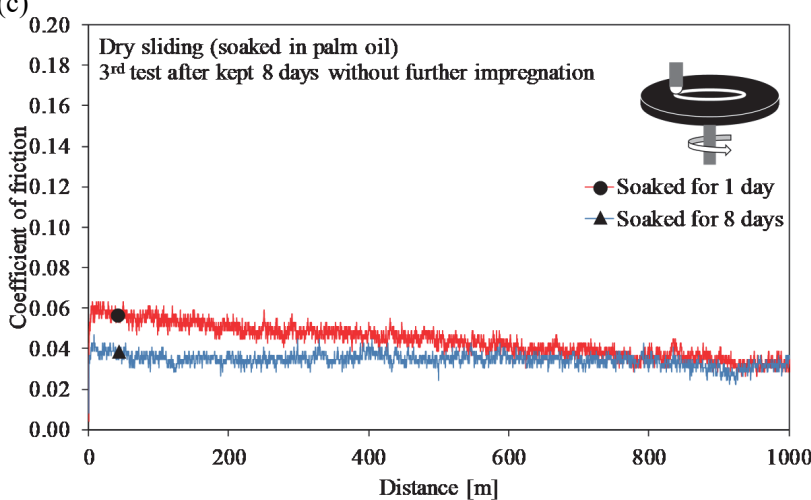

Fig. 5 Effect of soaking time on friction coefficient of PKAC polymer composite impregnated with palm oil: (a) $1^{\text {st }}$ test, (b) $2^{\text {nd }}$ test after kept 2 days without further impregnation and (c) $3^{\text {rd }}$ test after kept 8 days without further impregnation

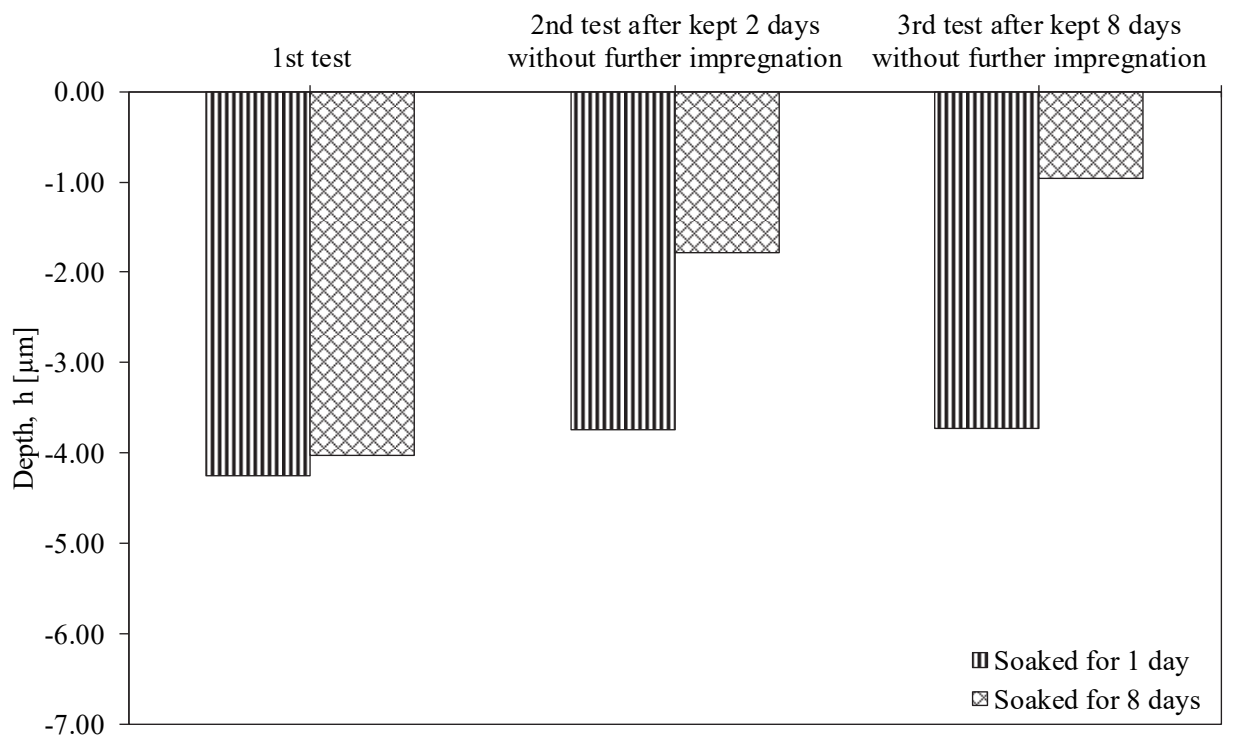

Fig. 6 Effect of soaking time on residual depth of PKAC polymer composite impregnated with palm oil 
(a)

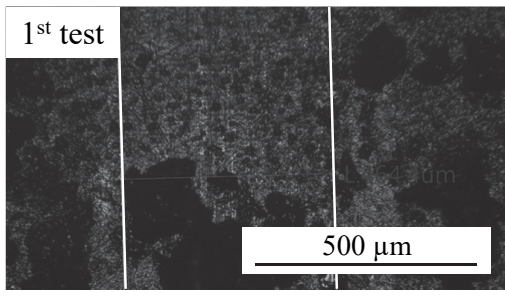

(b) $1^{\text {st }}$ test

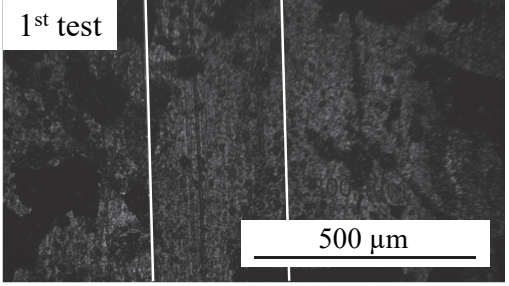

$2^{\text {nd }}$ test: After kept for 2 days

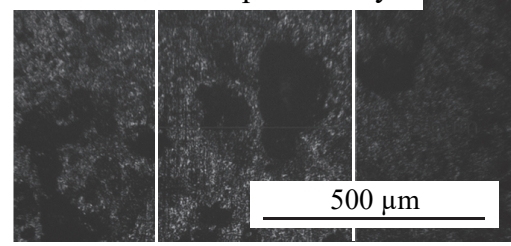

$2^{\text {nd }}$ test: After kept for 2 days

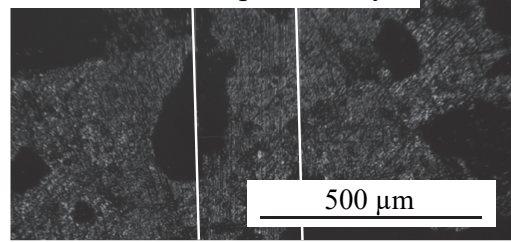

$3^{\text {rd }}$ test: After kept for 8 days

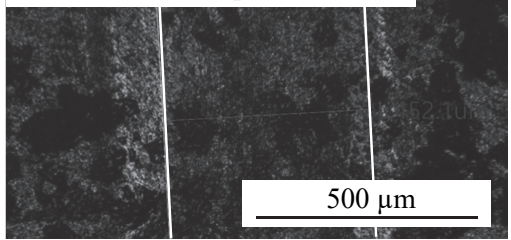

$3^{\text {rd }}$ test: After kept for 8 days

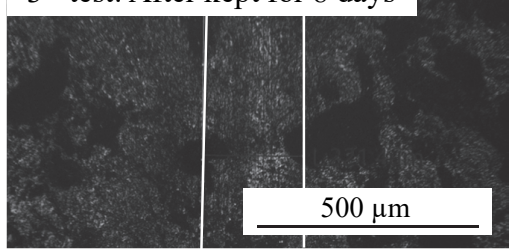

Fig. 7 Optical image of PKAC polymer composite impregnated with palm oil: (a) After soaked for 1 day and (b) after soaked for 8 days

\section{Conclusion}

There is considerable decrease in the friction of lubricantimpregnated PKAC polymer composite although there is an increase in the residual depth due to plastic deformation, in comparison to the composite not soaked in the lubricant. Water impregnation caused a sudden increase in the coefficient of friction initially for a few hours following which it was comparatively constant. However, the sample impregnated with palm and paraffin oils can soak up the lubricant at the time of its inflow and preserve it for some time prior to the subsequent inflow. There is a substantial effect of soaking time on the coefficient of friction and residual depth. Wear grooves are observed on the worn surface of sample impregnated with water and paraffin oil after the sample is kept for 2 and 8 days. In contrast, no wear is observed on the surface of all samples impregnated with palm oil. To sum up, this research recommends palm oil use as a medium of impregnation for PKAC polymer composite. In future, a comprehensive study regarding the mechanisms of friction reduction is necessary since the utilisation of the bio-based lubricant to get better performance in comparison to the synthetic oil will be more useful.

\section{Acknowledgement}

The authors gratefully acknowledge contributions from the members of the Green Tribology and Engine Performance (G-Tribo-E) research group, Universiti Teknikal Malaysia Melaka. This research is supported by a grant from the Universiti Teknikal Malaysia Melaka (grant number: PJP/2019/ $\operatorname{FKM}(10 \mathrm{~A}) / \mathrm{S} 01683)$.

\section{References}

[1] Society of Tribologist and Lubrication Engineers (STLE), "Report on Emerging Issues \& Trends," 2017.
[2] Mohmad, M., Abdollah, M. F. B., Khudhair, A. Q., Tamaldin, N., Amiruddin, H. and Zin, M. R. B. M., "Physical-Mechanical Properties of Palm Kernel Activated Carbon Reinforced Polymeric Composite: Potential as a Self-Lubricating Material," Jurnal Tribologi, 17, 2018, 77-92.

[3] Tahir, N. A. M., Abdollah, M. F. B., Hasan, R. and Amiruddin, H., "The Effect of Sliding Distance at Different Temperatures on the Tribological Properties of a Palm Kernel Activated Carbon-Epoxy Composite," Tribology International, 94, 2016, 352-359.

[4] Abdollah, M. F. B., "Agricultural-Waste Based Polymeric Composite as a New Self-Lubricating Antifriction Material," Proceedings of SAKURA Symposium on Mechanical Science and Engineering, 2017, 8-10.

[5] Hashmi, S. A. R., Dwivedi, U. K. and Chand, N., “Graphite Modified Cotton Fibre Reinforced Polyester Composites under Sliding Wear Conditions," Wear, 262, 11-12, 2007, 1426-1432.

[6] Menezes, P. L., Rohatgi, P. K. and Lovell, M. R., "Studies on the Tribological Behavior of Natural Fiber Reinforced Polymer Composite," Green Tribology, Springer, Berlin, Heidelberg, 2012, 329-345.

[7] Koronis, G., Silva, A. and Fontul, M., “Green Composites: a Review of Adequate Materials for Automotive Applications," Composites Part B: Engineering, 44, 1, 2013, 120-127.

[8] Correa, C. E., Betancourt, S., Vázquez, A. and Gañan, P., “Wear Performance of Vinyl Ester Reinforced with Musaceae Fiber Bundles Sliding against Different Metallic Surfaces," Tribology International, 109, 2017, 447-459.

[9] Karthikeyan, S., Rajini, N., Jawaid, M., Winowlin Jappes, J. T., Thariq, M. T. H., Siengchin, S. and Sukumaran, J., "A Review on Tribological Properties of Natural Fiber Based Sustainable Hybrid Composite," Proceedings of the Institution of Mechanical Engineers, Part J: Journal of Engineering Tribology, 231, 12, 2017, 1616-1634.

[10] Mang, T. and Lingg, G., "Base Oils," Lubricants and Lubrication, Wiley, Weinheim, Germany, 2017, 51-82.

[11] Akpan, E. I., Wetzel, B. and Friedrich, K., "A Fully Biobased Tribology Material Based on Acrylic Resin and Short Wood Fibres," Tribology International, 120, 2018, 381-390. 